\title{
Müller Cell-Derived PEDF Mediates Neuroprotection via STAT3 Activation
}

\author{
Wolfram Eichler ${ }^{a} \quad$ Helena Savković-Cvijića Susanne Bürger ${ }^{a} \quad$ Mike Beck $^{\mathrm{a}}$ \\ Manuela Schmidt ${ }^{a}$ Peter Wiedemann ${ }^{a}$ Andreas Reichenbach ${ }^{b}$ \\ Jan Darius Unterlauft ${ }^{\mathrm{a}}$
}

${ }^{a}$ Department of Ophthalmology and Eye Hospital, Leipzig University, Leipzig, ${ }^{b}$ Paul Flechsig Institute for Brain Research, Pathophysiology of Glia, Leipzig University, Leipzig, Germany

\section{Key Words}

Neuroprotection • Retinal ganglion cells • Müller cells • PEDF

\begin{abstract}
Background/ Aims: This study was performed to reveal signaling pathways exploited by pigment epithelium-derived factor (PEDF) derived from retinal (glial) Müller cells to protect retinal ganglion cells (RGCs) from cell death. Methods: The survival of RGCs was determined in the presence of conditioned culture media (MCM) from or in co-cultures with Müller cells. The significance of PEDF-induced STAT3 activation was evaluated in viability assays and using Western blotting analyses and siRNA-transfected cells. Results: Secreted mediators of Müller cells increased survival of RGCs under normoxia or hypoxia to a similar degree as of PEDF- or IL-6-exposed cells. PEDF and MCM induced an increased STAT3 activation in RGCs and R28 cells, and neutralization of PEDF in MCM attenuated STAT3 activation. Inhibition of STAT3 reduced PEDF-promoted survival of RGCs. Similar to IL-6, PEDF induced STAT3 activation, acting in a dose-dependent manner via the PEDF receptor (PEDF-R) encoded by the PNPLA2 gene. Ablation of PEDF-R attenuated MCM-induced STAT3 activation and compromised the viability of PEDF-exposed R28 cells. Conclusions: Müller cells are an important source of PEDF, which promotes RGC survival through STAT3 activation and, at least in part, via PEDF-R. Enhancing the secretory function of Müller cells may be useful to promote RGC survival in retinal neurodegenerative diseases.
\end{abstract}

\section{Introduction}

Pigment epithelium-derived factor (PEDF) is a multifunctional secreted $50-\mathrm{kDa}$ glycoprotein with neuroprotective, neurotrophic, angioinhibitory, antioxidant, antiinflammatory, antithrombotic and antitumorigenic actions. Numerous studies have revealed that under several physiological and pathological conditions PEDF affects important cellular processes, regulating survival, proliferation, differentiation and morphogenesis [1]. PEDF- 
mediated neuroprotection and inhibition of angiogenesis are of particular importance for integrity and function of the retina (for review, see Ref [2]).

Retinal neurod egenerative diseases are among the leading causes of blindness worldwide [3-5]. A common feature of these widespread diseases such as glaucoma, hypertensive and ischemic retinopathies is the demise of retinal ganglion cells (RGCs), which underlies impaired visual acuity and may ultimately lead to blindness. Recent treatment approaches of retinal neurodegenerative diseases have proven hardly effective, and attempts to restore the visual function have rarely been successful. Despite the clinical significance and high prevalence of neurodegenerative diseases of the retina, cellular and molecular mechanisms promoting neuronal cell death loss remain poorly understood. However, understanding the role of important mediators of cell-cell communication and their mechanism of action is critical for developing novel strategies to treat these serious retinal eye diseases.

A number of mechanisms have been considered to be responsible for neuronal demise under sight-threatening conditions. Activation of glutamate receptors, oxidative stress, nitric oxide (NO), inflammatory conditions and deprivation of neurotrophic factors are all implicated in retinal ganglion cell (RGC) degeneration [6]. We have recently developed a cell culture model based on the co-culture of primary RGCs and retinal glial (Müller) cells, taking into account that Müller cells are able to respond to various pathological external influences and can provide a supportive milieu for the viability of retinal neuronal cells. Noteworthy, Müller cells are an important source of neuroprotectants such as brain-derived neurotrophic factor, vascular endothelial growth factor-A, leukemia inhibitory factor, ciliary neurotrophic factor (CNTF), glial-derived neurotrophic factor (GDNF), basic fibroblast growth factor (bFGF), and pigment epithelium-derived factor (PEDF) [7-16].

Its anti-angiogenic and neuroprotective properties make PEDF an ideal candidate molecule for the treatment of ischemic retinal diseases. Importantly, neuroprotective activities of PEDF have been demonstrated in conditions of ischemia/ reperfusion injury [17, 18], glutamate excitotoxicity [19], retinal light damage [20], peroxide-mediated oxidative stress [21] as well as in models of inherited retinal degeneration [22, 23]. We have previously demonstrated that Müller cell-derived PEDF exerts neuroprotective effects on RGCs and that the PEDF-promoted increase of RGC survival was, at least partly, due to the activation of the NF- $\kappa B$ signaling pathway $[14,24]$.

Previous studies suggest that PEDF binds to the patatin-phospholipase domaincontaining (PNPLA2) gene-encoded PEDF receptor (PEDF-R), which is also known as human transport secretion protein (TTS)-2.2 or $\mathrm{Ca}^{2+}$-independent adiponutrin/ desnutrin/ ATGLhomologous phospholipase A2 $\zeta$ [25]. PEDF-R is involved in the neuroprotective actions mediated by PEDF [26]. There is a variety of intracellular signaling pathways that may play a role in PEDF-mediated pro-survival gene expression during periods of oxidative stress, hypoxia or even in response to trophic factor withdrawal from RGCs [27]. A potentially important pathway, which promotes RGC survival and may cause a prolonged viability of RGCs under unfavourable conditions, is the Janus kinase (JAK) 2/signal transducers and activators of transcription (STAT) 3 pathway. There is evidence from animal models to suggest that the interleukin (IL)-6 family cytokine, CNTF, exerts survival-promoting effects on RGCs [28-30]. For example, CNTF caused a significant protection of RGCs in experimental glaucoma, acted as a survival factor in an optic nerve axotomy model or in a model of NO-induced cell death [28-30], and it has been suggested that JAK/STAT3 signaling is an important pathway involved in the neuroprotective actions of CNTF [30, 31]. Moreover, it has been demonstrated that CNTF acts through JAK/STAT3 pathway activation to switch mature RGCs to a regenerative state, stimulating axon regeneration and increased survival of RGCs under pathologic external influences [32-34].

Given the strong evidence of the importance of STAT3-inducing cytokines for neuroprotection the present study was undertaken to explore whether Müller cell-derived PEDF promotes increased RGC viability through STAT3 activation. We also examined the possibility of a concerted action of PEDF and the prototypic STAT3 signaling inducer, IL-6, to promote RGC survival under hypoxia. We propose that the STAT3 pathway is a promising 


\section{Cellular Physiology Cell Physiol Biochem 2017;44:1411-1424

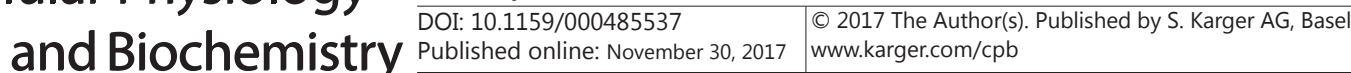

Eichler et al.: Retinal Ganglion Cell Survival: PEDF and STAT3 Activation

target for an adjuvant therapeutic approach, with STAT3 activation that is induced by Müller cell-derived PEDF.

\section{Materials and Methods}

\section{Animals and cell cultures}

Animals were treated in accordance with the European Union Directive (2010/63/EU) and German Law on Protection of Animals. Procedures were approved by local authorities (University of Leipzig Medical Faculty; Landesdirektion Sachsen). Cell culture media and supplements were from Invitrogen (Karlsruhe, Germany). Primary rat Müller cells and mouse RGCs were isolated and cultured as previously described [14, 35]. Briefly, retinae from six- to nine-day-old Long-Evans rats were isolated and mechanically dissociated by careful homogenization. After digesting the retinal tissue with the bacterial protease nagarse (subtilisin A, $1 \mathrm{mg} / \mathrm{ml}$; MP Biomedicals; Eschwege, Germany) and subsequent filtration cells were resuspended and cultured in Dulbecco's minimal essential medium (DMEM) $/ 10 \%$ fetal calf serum (FCS). Müller cells were routinely evaluated by immunofluorescence staining using a monoclonal antibody against vimentin. RGCs were isolated from seven days old mice. In brief, retinae were dissected, digested with papain (160 U/ $\mathrm{ml})$ and DNase $(200 \mathrm{U} / \mathrm{ml})$, passed through a $20-\mu \mathrm{m}$ nylon mesh, and the cell suspension was added to immunopanning plates. Contaminating microglial cells were removed by means of a rabbit anti-macrophage antibody (WAK Chemie, Steinbach, Germany) by incubating cells on an anti-rabbit IgG-coated petri dish, followed by RGC selection on plates sequentially coated with goat anti-mouse IgG and mouse anti-Thy 1.2 (clone F7D5; Serotec, Düsseldorf, Germany). Purified RGCs were then plated on poly-D-lysine (MW $40 \mathrm{kDa}$; $5 \mu \mathrm{g} / \mathrm{ml}$ )-coated glass coverslips at 600 cells $/ \mathrm{mm}^{2}$ and cultured for seven days $\left(37^{\circ} \mathrm{C}, 5 \% \mathrm{CO}_{2}\right)$ in complete neurobasal medium. Cell viability was routinely verified under a phase contrast microscope. Coverslips carrying viable RGCs were only used in case of distinct neurite sprouting, and only cultures of pure RGCs showing no trace of glial contamination were selected for further studies. Staining of neurofilament $\mathrm{H}$ was routinely performed to confirm neuronal identity of cells. Immortalized retinal progenitor cells (R28 cells) $[36,37]$ were a kind gift of Dr Katharina Bell (Department of Ophthalmology, Johannes Gutenberg University Mainz, Germany) and routinely maintained in DMEM containing 10\% FCS, non-essential amino acids and vitamins. R28 cells have long been used for in-vitro studies; they express neuronal markers among them are the RGC-specific molecules, CD90/Thy 1.1 and 2G12 [36, 37]. Furthermore, R28 cells express the PNPLA2 gene-encoded PEDF receptor (PEDF-R [25, 38].

\section{Müller cell-RGC co-culture experiments}

Primary rat Müller cells were cultured on coverslips up to $90 \%$ of confluence and then briefly washed with Hanks' balanced salt solution. Müller cells $\left(8-10 \times 10^{4}\right)$ grown on two coverslips and one coverslip with RGCs $\left(\sim 5 \times 10^{4}\right)$ were co-cultured in a single well of a 6-well plate for $24 \mathrm{~h}$ in a minimal neurobasal medium. This approach resulted in physical separation of the two cell populations but allowed cells to access media in each of the wells [14].

\section{Hypoxia and treatment of cells}

Experiments with RGCs, Müller cells and R28 cells were conducted in serum-free and growth factordeprived medium (DMEM $/ 1 \mathrm{mg} / \mathrm{ml}$ bovine serum albumin [BSA]) for $24 \mathrm{~h}$ either under normoxic or hypoxic $\left(0.2 \% \mathrm{O}_{2}\right)$ conditions (each at $\left.5 \% \mathrm{CO}_{2}\right)$. Where indicated, RGCs were cultured in the presence or absence of recombinant human PEDF produced by mouse myeloma cells (R\&D Systems, Wiesbaden) or mouse IL-6 $(10 \mathrm{ng} / \mathrm{ml}$; R\&D Systems). If necessary, R28 cells were preincubated for $1 \mathrm{~h}$ with $5 \mu \mathrm{M}$ 6-nitrobenzo [b] thiophene-1, 1-dioxide (Stattic), a synthetic blocker acting as an inhibitor of STAT3 (Merck Chemicals, Schwalbach, Germany), and subsequently treated with PEDF and/ or IL-6 in the presence of the blocker. Cells cultured in the absence of Stattic were treated with vehicle (ethanol). To mimic conditions that develop as a result of a milieu containing Müller cell-derived soluble factors, RGCs or R28 cells were exposed to Müller cell-conditioned media (MCM), recombinant PEDF (range $50-250 \mathrm{ng} / \mathrm{ml}$ ) and/ or IL-6 (10 ng/ml).

\section{RNA interference}

To determine PEDF-induced STAT3 activation in R28 cells and cell viability following PEDF-R ablation, cells were transfected in 6-well plates using Lipofectamine ${ }^{\circledR}$ RNAiMAX (Invitrogen) and 60 pmol of siRNA 


\section{Cellular Physiology Cell Physiol Biochem 2017;44:1411-1424

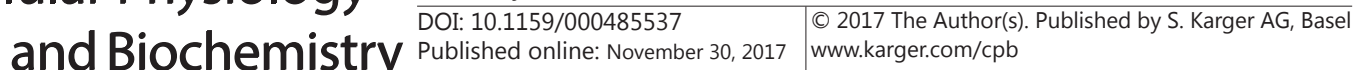

Eichler et al.: Retinal Ganglion Cell Survival: PEDF and STAT3 Activation

targeting rat PEDF-R (sense: GCG GCA UUU CAG ACA ACU U[dT][dT], antisense: AAG UUG UCU GAA AUG CCG C[dT][dT]). Parallel cultures treated with control siRNA (Qiagen, Cat\# 1027292 and Santa Cruz, Cat\# sc37007) were included. Downregulation of PEDF-R mRNA expression levels was controlled using real-time PCR. Twenty-four hours after transfection cells were plated in microwell plates, cultured for further $24 \mathrm{~h}$, and used in viability assays or stimulated to induce STAT3 activation as indicated below.

\section{Cell viability assays}

RGC survival was assessed by a live-dead assay as described earlier [14]. Briefly, RGCs were exposed to calcein acetoxymethyl ester (Calcein-AM; Molecular Probes, Inc., Eugene, OR) for $2 \mathrm{~h}$, and labeled live cells were counted. The total number of cells was assessed by counter-staining with 4'-6-diamidino-2phenylindole (DAPI). To obtain a survival percentage, total numbers of RGCs per visual field were assessed by counting DAPI-positive nuclei and compared to numbers of viable cells by counting cell bodies that metabolized Calcein-AM. Ten visual fields were inspected on each coverslip at $200 \mathrm{x}$ magnification.

\section{Analysis of STAT3 activation by Western blotting and immunofluorescence staining of cells}

R28 cells grown in six-well plates or RGCs plated on glass coverslips were starved in serum-free DMEM overnight. Cells were treated with or without recombinant PEDF and/ or IL-6 or incubated with MCM for $30 \mathrm{~min}$. If indicated, MCM were preincubated with a preservative-free bioactivity-neutralizing antibody against PEDF ( $3 \mu \mathrm{g} / \mathrm{ml}$; BioProducts Maryland, Middletown, USA). Normal rabbit IgG ( $3 \mu \mathrm{g} / \mathrm{ml}$ ) served as a control. R28 cultures were quenched by washing with ice-cold PBS/1 mM sodium orthovanadate, and cells were extracted for $30 \mathrm{~min}$ in ice-cold lysis buffer (62.5 mM Tris-HCl, pH 7.6, $1 \mathrm{mM}$ EDTA, $150 \mathrm{mM} \mathrm{NaCl}$, 1\% Triton X-100, $1 \mathrm{mM}$ phenylmethylsulfonyl fluoride) supplemented with a phosphatase inhibitor mix (Roche Applied Science). Lysates were centrifuged at 10, $000 \mathrm{x} g$ (5 min), and supernatants were subjected to SDS-PAGE, with equal amounts of protein that were separated and transferred to PVDF membranes, which were subsequently processed for Western Blotting. Immunoblots were blocked with TBS/ 0.05\% Tween-20, 10\% (v/v) Rotiblock (Roth, Karlsruhe, Germany) and probed with rabbit antibodies against STAT3 or phosphorylated STAT3, Tyr705 (both purchased from New England Biolabs, Frankfurt/M., Germany; diluted in TBS/ $0.05 \%$ Tween-20, 5\% BSA), followed by incubation with goat anti-rabbit IgG conjugated to alkaline phosphatase (Dianova). Bands were developed with nitroblue tetrazolium $(0.5 \mathrm{mg} /$ $\mathrm{ml})$ / 5-bromo-4-chloro-3-indolyl phosphate $(0.25 \mathrm{mg} / \mathrm{ml})$ dissolved in $100 \mathrm{mM}$ Tris- $\mathrm{HCl}, \mathrm{pH} 9.6,100 \mathrm{mM}$ $\mathrm{NaCl}, 1 \mathrm{mM} \mathrm{MgCl}_{2}, 1 \mathrm{mM} \mathrm{CaCl}_{2}$. Alternatively, RGCs were were fixed in 4\% paraformaldehyde, treated with PBS/1\% DMSO/0.3\% Triton X-100/5\% normal goat serum $(2 \mathrm{~h})$ and incubated overnight $\left(4^{\circ} \mathrm{C}\right)$ with an antibody against phosphorylated STAT3 (see above). After washing three times with PBS/2\% BSA, cells were incubated for $2 \mathrm{~h}$ with cyanine (Cy) 3-tagged polyclonal goat anti-mouse IgG (Dianova). Cells were washed, counterstained with DAPI and mounted.

\section{RT-PCR and quantitation of PCR products}

Total RNA was prepared from cells, treated with DNase I (Life Technologies) and subjected to reverse transcription using standard procedures. Complemetary DNA (cDNA) was synthesized from $1 \mu \mathrm{g}$ total RNA in a 20- $\mu$ l reaction containing $200 \mathrm{U}$ of Superscript II reverse transcriptase (Life Technologies), 500 $\mu \mathrm{M}$ of dNTPs, $5 \mathrm{mM}$ DTT and $0.5 \mu \mathrm{g}$ oligo(dT) $)_{15}$ (BioTeZ, Berlin, Germany). Amplification of cDNA was carried out using 0.5 U CrimsonTaq DNA polymerase (New England Biolabs, Frankfurt/Main, Germany) in a buffer containing $12.5 \mathrm{mM}$ Tricine- $\mathrm{HCl}, \mathrm{pH} 8.5,42.5 \mathrm{mM} \mathrm{KCl}, 1.5 \mathrm{mM} \mathrm{MgCl}, 6 \%$ dextran and 100 $\mu \mathrm{M}$ dNTPs. Primers (125 nM) used for amplification were the following: 5'-AGAGATGTGCAAACAGGG-3' and 5'-GCACTGGTAGCATGTTGG-3' (mouse/ rat PNPLA2) or 5'-CATCATAAATCTCAAGAGGACGTG-3' and 5'-TGGATCTGGTTAGTGAAGTTTC-3' (mouse/ rat laminin receptor 1/ RPSA). Real-time PCR was used to determine PNPLA2 expression using $\beta$-actin transcript levels for normalization. Aliquots of cDNA were treated with Maxima SYBR Green mastermix (Thermo Fisher Scientific, Braunschweig, Germany) and 200 $\mathrm{nM}$ of primers specific for segments of mouse/ rat PNPLA2 or rat $\beta$-actin (5`-GAAACTACATTCAATTCCATC-3` and $5^{`}$-GGAGCAATGATCTTGATCTT-3') cDNA. Samples were denatured at $95^{\circ} \mathrm{C}$ for 6 min, followed by 45 cycles of melting at $95^{\circ} \mathrm{C}$ for $10 \mathrm{~s}$, annealing at $58.5^{\circ} \mathrm{C}$ for $25 \mathrm{~s}$, and elongation at $72^{\circ} \mathrm{C}$ for $25 \mathrm{~s}$. Data were checked for homogeneity by dissociation curve analysis. Fluorescence changes were monitored after each cycle, and $C \mathrm{t}$ (threshold cycle) values for amplification of target genes were determined.

\section{KARGER}




\section{Cellular Physiology Cell Physiol Biochem 2017;44:1411-1424 \begin{tabular}{l|l} 
and Biochemistry Published 10.1159/000485537 & $\begin{array}{l}\text { (c) } 2017 \text { The Author(s). Published by S. Karger AG, Basel } \\
\text { www.karger.com/cpb }\end{array}$
\end{tabular}}

Eichler et al.: Retinal Ganglion Cell Survival: PEDF and STAT3 Activation

Analyses of PEDF-R protein expression

PEDF-R protein levels in cell lysates were assessed by Western blotting. Expression of cell surface PEDF-R on R28 cells was analyzed by flow cytometry. For Western blotting, cells were extracted on ice and lysates were processed as indicated in the penultimate paragraph. Blots were probed with polyclonal antirat PEDF-R/PNPLA2 (R\&D Systems) or rabbit anti- $\beta$-actin (New England Biolabs) antibodies and further developed with appropriate secondary antibodies. For flow cytometry, cells were detached by treatment with Hepes (20 mM)-buffered Hank's balanced salt solution (HBSS), pH 7.4, $2.5 \mathrm{mM}$ EDTA (5 min, $37^{\circ} \mathrm{C}$ ) and resuspended in $10 \mathrm{mM}$ Hepes, pH 7.6, HBSS, $1 \mathrm{mM} \mathrm{CaCl}, 1 \mathrm{mM} \mathrm{MgCl}_{2}, 0.05 \% \mathrm{NaN}_{3}, 1 \%$ BSA supplemented with $5 \%$ normal donkey serum. Cells were then incubated with anti-rat PEDF-R/PNPLA2 or non-immune IgG overnight at $4{ }^{\circ} \mathrm{C}$, washed and exposed to Cy2-conjugated donkey anti-goat IgG (Dianova, Hamburg, Germany). After washing, the samples were analyzed with a flow cytometer (FACScan; BD Biosciences, Mountain View, CA) using CELLQuest software. Gates were set to exclude nonviable cells, and histograms were recorded. Histograms plot the cell number (y-axis) versus fluorescence intensity on a logarithmic scale (x-axis).

\section{Data analysis}

All data are expressed as means \pm SEM. Statistical comparisons were performed using standard oneway ANOVA, and significance was accepted at $P<0.05$.

\section{Results}

\section{PEDF and IL-6 stimulation cause a comparable increase in RGC survival rates}

We have previously shown that PEDF increases the survival of RGCs in vitro following growth factor deprivation and under hypoxic conditions $[14,24]$. In the present study we have examined the pro-survival effects of PEDF and IL- 6 and found that both factors had comparable effects on RGCs in 24-h cultures. Compared to factor-free control cultures, the number of viable RGCs (means \pm SEM; $n=7$ ) increased $(P<0.01$ ) from $58.4 \pm 3.0 \%$ to 71.5 $\pm 4.0 \%$ and from $42.4 \pm 5.3 \%$ to $56.1 \pm 3.5 \%$ after PEDF treatment and to $79.5 \pm 6.2 \%$ and $58.2 \pm 6.8 \%$ after IL- 6 exposure, each under normoxia and hypoxia, respectively. However, PEDF and IL- 6 did not act synergistically on RGC survival, when compared to cultures in the presence of either factor alone (Fig. 1).

Fig. 1. PEDF and IL-6 stimulate RGC survival. RGCs were deprived of trophic factors and incubated for $24 \mathrm{~h}$ in the presence or absence of PEDF $(50 \mathrm{ng} / \mathrm{ml})$ and IL-6 (10 ng/ml). Viability of RGCs was determined in homotypic RGC cultures after adding both mediators, each alone or in combination, or in the presence of co-cultured Müller cells (MC). A: A bar chart demonstrating the summary of seven experiments. Significant differences to normoxic $\left(* * \mathrm{P}<0.01,{ }^{* * *} \mathrm{P}<0.001\right)$ or hypoxic $(\bullet \mathrm{P}<0.05, \cdot \bullet \mathrm{P}<0.01)$ homotypic control cultures are indicated (means \pm SEM). B: Representative microscopic images showing viable RGCs (green) in the presence or absence of PEDF and/ or IL-6 as well as in Müller cell-RGC co-cultures. The number of DAPI-positive nuclei were counted and compared to numbers of viable cells that metabolized Calcein-AM.

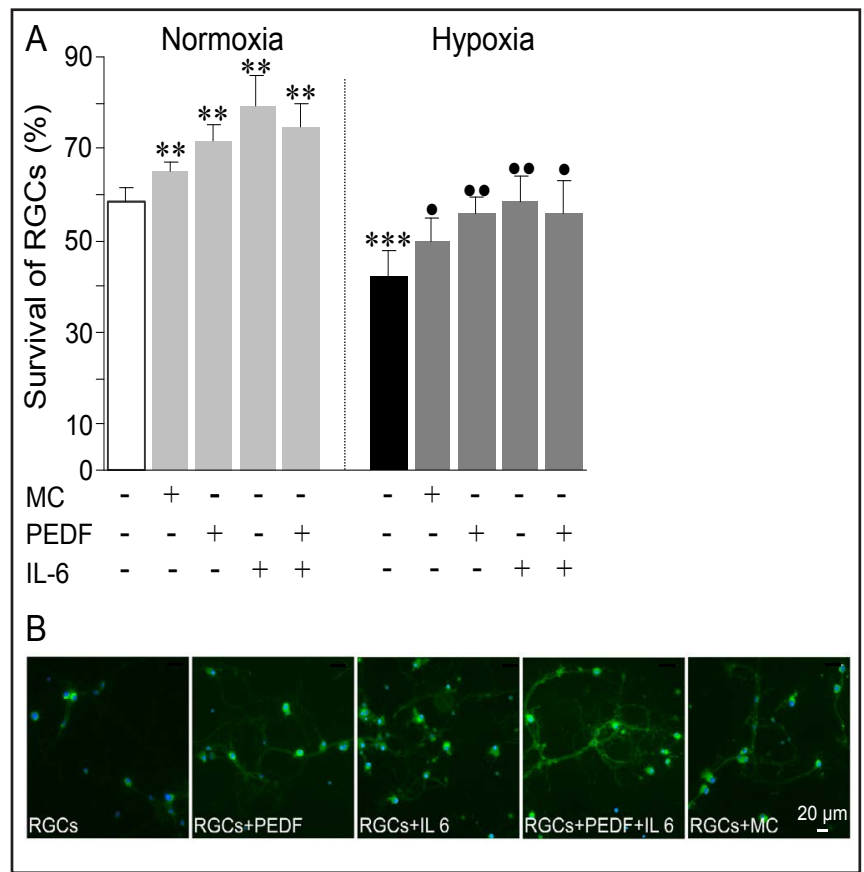




\section{Cellular Physiology Cell Physiol Biochem 2017;44:1411-1424

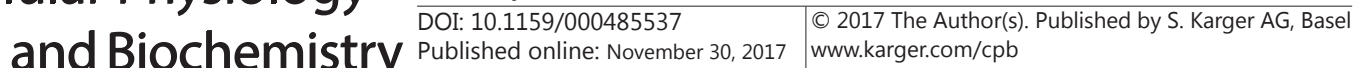

In earlier experiments we demonstrated that PEDF released from Müller cells can promote RGC survival. When co-cultured with Müller cells under normoxia or hypoxia, RGCs demonstrated an increased survival to a similar degree as in PEDF- and IL-6-stimulated cultures (Fig. 1). Culture media of Müller cells contain PEDF $[8,39]$. We found that culture media of Müller cells conditioned for $24 \mathrm{~h}$ under normoxia (NCM) or hypoxia $\left(0.2 \% \mathrm{O}_{2}\right.$; HCM) stimulated RGC survival (Fig. 2A). Interestingly, these media concomitantly induced an increased STAT3 activation in R28 cells, although there was no obvious difference in the STAT3 activation state obtained either with NCM or HCM (Fig. 2B). These findings raised the question of whether Müller cell-derived PEDF exerts its pro-survival effects by stimulating the JAK2/STAT3 signaling pathway.

\section{Müller cell-derived PEDF induces STAT3 activation in R28 cells}

Using antibodies to phosphorylated tyrosine (Y705) in STAT3 we found that, compared to unstimulated cells, PEDF-treated RGCs displayed weaker cytoplasmic labeling. Instead, PEDF-treated RGCs demonstrated a preference of nuclear staining (Fig. 3A, upper panel). In further experiments STAT3 activation was analyzed with R28 cells, due to the limited availability of primary RGCs and in consideration of a demonstrable sensitivity of R28 cells towards the survival-promoting action of PEDF $[38,40]$. To determine whether PEDF induces signaling through STAT3, we exposed R28 cells to Müller cell-conditioned media (MCM) and, comparably, treated the cells with recombinant PEDF. PEDF caused phospho-STAT3 accumulation in the nucleus of R28 cells indicating PEDF-induced nuclear distribution and activation of STAT3 (Fig. 3A, lower panel). A time course analysis revealed an increase in STAT3 phosphorylation as early as 10-20 min post-stimulation (Fig. 3B). Furthermore, PEDF increased the phosphorylation state of STAT3 in R28 cells in a dose-dependent manner (Fig. 3C). The degree of STAT3 activation in PEDF-treated cells was comparable to that detected in IL-6-exposed cells. However, co-stimulation of R28 cells with both PEDF and IL-6 did not induce a stronger activation of STAT3 compared to R28 cells stimulated with PEDF or IL-6 alone (Fig. 3D). When assaying the effects of MCM on signaling we took advantage of a neutralizing anti-PEDF antibody, which we had successfully used before to neutralize PEDFmediated functions in retinal endothelial cells [41]. In the present study this antibody was employed to deplete glia-conditioned media from PEDF. These experiments revealed that increased STAT3 activation in R28 cells induced by soluble glial-derived mediators in MCM was impaired by anti-PEDF treatment (Fig. 3E), irrespective of whether the media were conditioned under normoxia or hypoxia (data not shown).

RGCs express PEDF-R encoded by the PNPLA2 gene [24], but not low-density lipoprotein receptor-related protein 6 [42], another putative receptor for PEDF (data not shown). However, findings from this study suggest that RGCs also express another molecule described previously as a PEDF receptor, i.e., the non-integrin 67-kDa laminin receptor,

Fig. 2. Müller cell-derived soluble mediators promote RGC survival and increase STAT3 activation in R28 cells. Serum-deprived cells were cultured in the absence or presence of culture media derived from Müller cells conditioned under normoxic (NCM) or hypoxic (HCM) conditions. A: Survival of RGCs: significant differences to NCMor HCM-free cultures in normoxia $\left({ }^{*} \mathrm{P}<0.05\right)$ or hypoxia $(\bullet \mathrm{P}<0.01)$ are indicated (means \pm SEM; $\mathrm{n}=6$ ). B: STAT3 activation: R28 cells were exposed to basal medium or NCM or HCM, and cell extracts were immunoblotted for phosphoSTAT3; immunodetection of total STAT3 was used as a loading control. Similar results were obtained in 3 independent experiments.

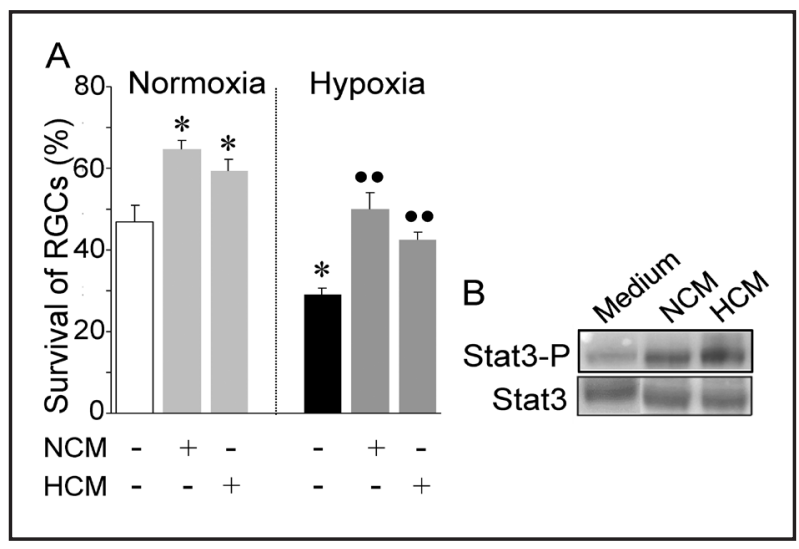


Fig. 3. PEDF induces STAT3 activation in RGCs and R28 cells. Serum-deprived cells were treated for 30 min with PEDF, NCM and, for comparison, IL-6. A: Immunofluorescence labeling of PEDF (250 ng/ml)-exposed RGCs (upper panel) and R28 cells (lower panel) demonstrated preferential localization of phosphorylated (Tyr 705) STAT3 in the nuclei compared to unstimulated cells (-PEDF'). Cells were stained with antibodies against phosphoSTAT3 (red). DAPI (blue) was used to co-stain the nuclei, merged images show combined phosphoSTAT3/DAPI staining. B-E: The state of PEDF-induced STAT3 phosphorylation in R28 cells was determined by Western blotting; representative blots show activated (phosphorylated) and total STAT3. B: PEDF (100 ng/ml) induces rapid STAT3 phosphorylation. Lysates were prepared from cells stimulated for $10,20,30$ and $60 \mathrm{~min}$, a single experiment is shown. C: STAT3 activation induced by different concentrations of PEDF or $10 \mathrm{ng} / \mathrm{ml}$ IL-6. D: PEDF $(100 \mathrm{ng} / \mathrm{ml})$ and IL-6 (10 ng/ml) do not synergistically stimulate STAT3 activation. E: Neutralizing the activity of PEDF partially reversed the effects of NCM on STAT3 activation (Med.: medium

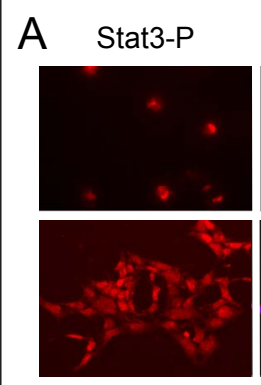

- PEDF

B
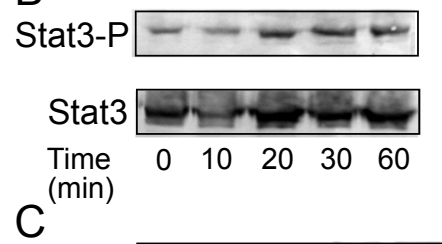

Stat3-P
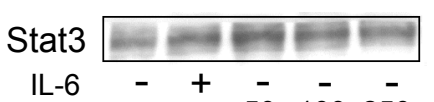
PEDF - - 50100250 $(\mathrm{ng} / \mathrm{ml})$

$\mathrm{D}$

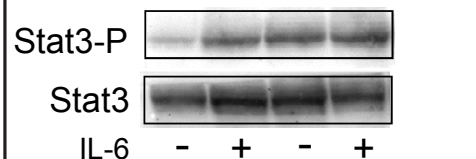

$E$

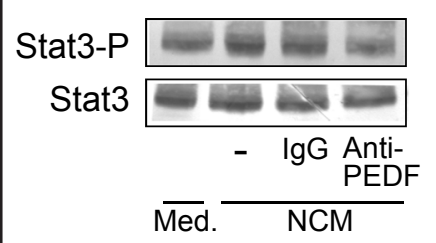

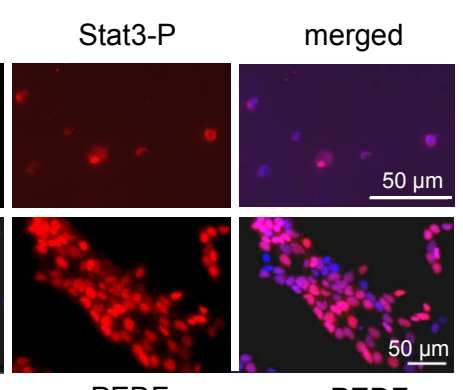

+ PEDF

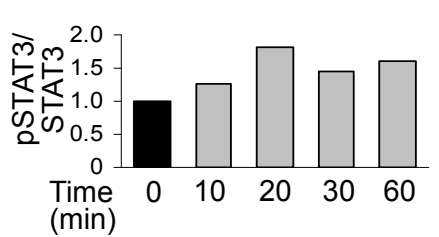

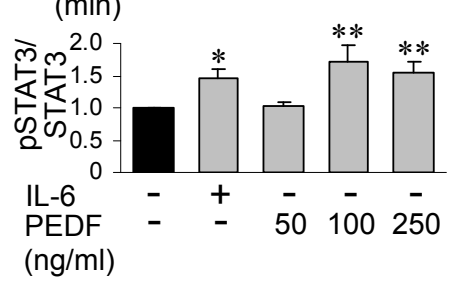

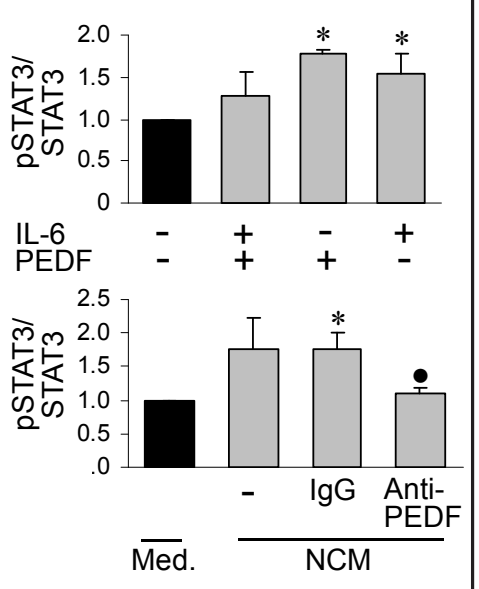
control). NCM were left untreated or preincubated $(1 \mathrm{~h})$ with either nonspecific normal rabbit IgG or a neutralizing anti-PEDF antibody (each at $1.6 \mu \mathrm{g} / \mathrm{ml}$ ) and added to the cells. The histograms to the right in B-E show amounts of phospho-STAT3 (pSTAT3) normalized to total STAT3 (pSTAT3/STAT3 ratio; ${ }^{*} \mathrm{P}<0.05$, ${ }^{* *} \mathrm{P}<0.01$ vs medium control; $\bullet P<0.05$, vs normal IgG-containing cultures; $\mathrm{C}: \mathrm{n}=6, \mathrm{D}$ and $\mathrm{E}: \mathrm{n}=3$ ).

ribosomal protein SA (RPSA) [43]. Moreover, we detected the expression of PEDF-R and RPSA mRNA transcripts in R28 cells (Fig. 4A). PEDF-R was included in further experiments aimed to investigate its role in mediating STAT3 activation and promoting RGC survival, based on previous findings showing that PEDF-R is expressed in the ganglion cell layer and by neuronal cells $[25,44]$.

To determine whether PEDF-R contributes to MCM-induced STAT3 activation we analyzed the degree of STAT3 phosphorylation in PEDF-R-depleted R28 cells following transfection with siRNA. RNA interference led to a reduced ( $\sim 5$-fold) PNPLA2 mRNA expression level, with concomitantly attenuated expression of total and cell surface PEDF-R protein (Fig. 4B). These experiments revealed that increased NCM- or HCM-induced activation of STAT3 in R28 cells was attenuated in PEDF-R-ablated cells, strongly suggesting that PEDF 
Fig. 4. A: RT-PCR experiments demonstrated the expression of the PEDF receptors RPSA and PEDF-R by RGCs and R28 cells. B: The effect of PNPLA2 siRNA in R28 cells compared to that of nontargeting control siRNA was determined by real-time PCR (left panel), Western blot analysis (middle panel) and flow cytometry (right panel). The results revealed reduced PNPLA2 mRNA expression $\quad\left({ }^{*} \mathrm{P}<0.05\right.$; means \pm SEM; $\mathrm{n}=$ 3), decreased total PEDF-R protein in R28 cell lysates and decreased number of cell surface PEDF-R-positive cells (in \%), respectively. PEDF-R is involved in PEDF-stimulated STAT3 activation in R28 cells induced by (C) secreted Müller cell-derived factors (MCM) or (D) PEDF. Transfected R28 cells were exposed to medium (Med.), (C) NCM, HCM or (D) PEDF $\left(100 \mathrm{ng} / \mathrm{ml}\right.$; ${ }^{*} \mathrm{P}<0.05,{ }^{\bullet} \mathrm{P}<0.01$, vs corresponding control siRNA-containing cultures; means \pm SEM; $n=3$ ).

exerts its pro-survival effect, at least partially, through PEDF-R on retinal neurons (Fig. 4C). These findings were consistent with data showing that PEDF-induced STAT3 activation was reduced in PEDF-R-depleted R28 cells (Fig. 4D). In contrast to these data we have not found evidence for altered PEDF-induced STAT3 activation when R28 cells were transfected with RPSA siRNA (data not shown). Together, these results suggest that Müller cell-derived PEDF induces STAT3 activation via interaction with PEDF-R and raises the question of whether this is an essential pathway to promote the survival of RGCs.

\section{STAT3 signaling is involved in PEDF-promoted RGC survival}

We further asked whether PEDF-induced STAT3 activation is involved in the control of RGC survival. Shown in Fig. 5A is that the viability of PEDF-exposed R28 cells was compromised when PEDF-R was depleted by means of siRNA. Neuronal survival of PNPLA2silenced cells exhibited a significant and $\sim 1.65$-fold decrease under normoxia, regardless of whether the cells were cultured in the presence $(P<0.01)$ or absence $(P<0.05)$ of PEDF $(n=$ $3)$. However, the survival rate of hypoxia-exposed PEDF-stimulated cells decreased 2.2-fold $(P<0.01)$, indicating that PEDF-promoted survival to a large degree is dependent on PEDF- $R$ expression. These results point to an important role for PEDF-R in neuronal survival and further suggest that PEDF signaling prolongs the survival of retinal neurons via PEDF-R.

Next, we cultured RGCs in the absence or presence of Stattic, a compound that was previously shown to selectively interfere with the STAT3 activation state and to abrogate STAT3 signaling [45]. As expected, preincubation with Stattic rendered R28 cells totally refractory to PEDF-induced STAT3 phosphorylation (Fig. 5B), and Stattic markedly inhibited the survival of IL-6-stimulated RGCs under normoxia and hypoxia (data not shown). Interestingly, Stattic also inhibited the survival of PEDF-exposed RGCs under normoxia 
Fig. 5. PEDF promotes neuronal survival via PEDF$R$ and through STAT3 activation. (A) PEDF-R depletion from R28 cells abrogates the PEDF-mediated increase in cellular survival under normoxia and hypoxia (PEDF: $250 \mathrm{ng} / \mathrm{ml} ; \cdot P<0.05, \cdot \bullet<0.01$, vs corresponding control siRNA-containing cultures; ${ }^{*} \mathrm{P}<0.05$, vs corresponding normoxic control culture; means \pm SEM; $n=3$ ). Note that due to the specific conditions of transfection PEDF-promoted neuronal survival reached statistical significance only under hypoxia. Cells cultured without trophic factors were exposed to PEDF for $30 \mathrm{~min}$ (B) or $24 \mathrm{~h} \mathrm{(C)}$ and in the presence or absence of the STAT3 inhibitor, Stattic (C, $10 \mu \mathrm{M})$. Stattic blocks (B) PEDF-induced STAT3 phosphorylation completely or (C) PEDF-promoted RGC survival under normoxia or hypoxia $\left({ }^{*} \mathrm{P}<0.05\right.$, ${ }^{*} \mathrm{P}<0.01$, vs normoxic control culture; $\bullet P<0.05$ vs hypoxic control culture; $\nmid \mathrm{P}<0.05$ vs $P$ EDF-exposed cultures without inhibitor; means \pm SEM; $n=8$ ). The Western blot shown in B is representative for five experiments with similar results.

and hypoxia (each 1.4-fold; Fig. 5C). These results suggest that STAT3 signaling is an important pathway that contributes to PEDFmediated RGC survival. Taken our present data together, there is strong evidence that PEDF prolongs RGC survival through STAT3

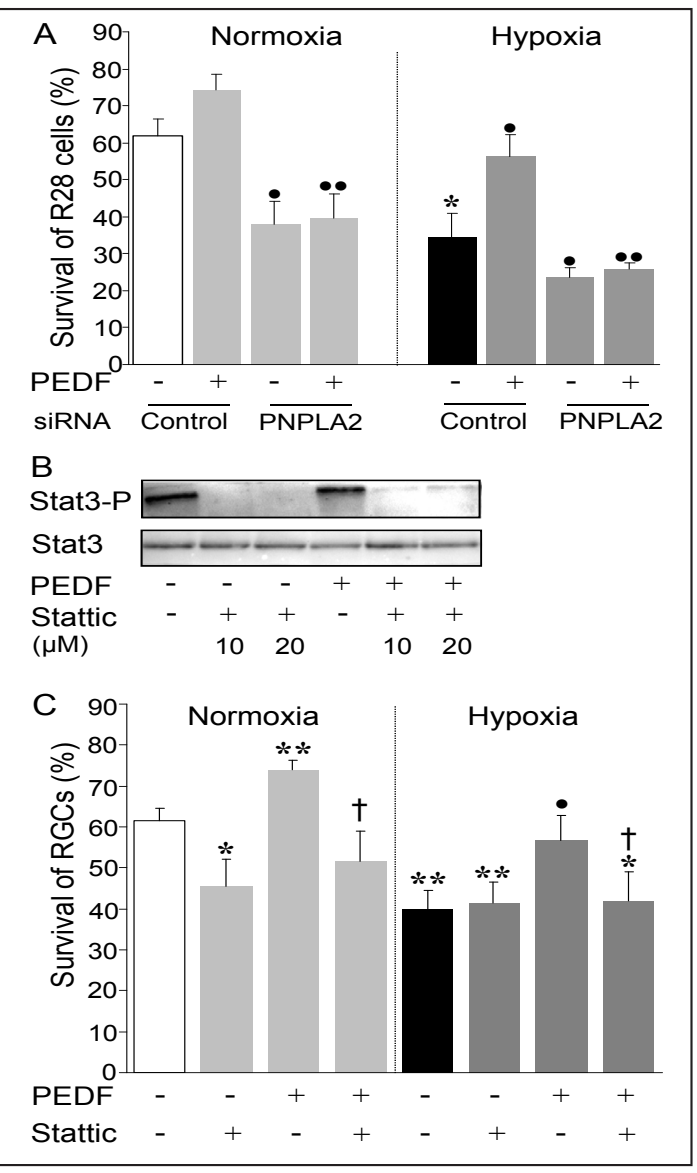
activation.

\section{Discussion}

Our findings suggest that Müller cell-derived PEDF promotes RGC survival via engagement of PEDF-R and through STAT3 activation. This gives rise to the assumption that PEDF plays an important role for the viability of RGCs and of other retinal neuronal cells. While the available information as to the combined action of individual survival factors and molecular events governing the protection of RGCs is rather fragmentary our data reveals that PEDF is an active neuroprotectant secreted by Müller cells. Neuronal cell death may be induced by growth factor withdrawal and extracellular death signals, which can be readily simulated and studied in cell culture. We have previously shown that cultured purified RGCs undergo apoptosis under hypoxia. Consistent with the survival-promoting effect of glial soluble mediators, co-cultured Müller cells attenuated the death of RGCs [24].

Soluble mediators produced by Müller cells contribute to tissue homeostasis of the developed retina under physiological and pathophysiological conditions [46]. This is reminiscent to the survival-promoting effects of the astrocytic glia in the optic nerve such as observed in glaucoma [47]. Müller cells provide trophic support for neonatal RGCs [48, 49], and neuroprotective factors secreted by activated retinal glial cells support the regeneration of injured RGCs [50]. In retinal degenerating diseases Müller cells are largely refractory to cell death. This may indicate that these cells are a permanent source of trophic factors during the chronic course of the disease, playing a key role in neuroprotection. The panel of Müller cell-derived released factors comprises, among others, bFGF, CNTF and GDNF [10, $15]$, as well as PEDF, as shown in this and our previous work [14, 24]. The action of PEDF 


\section{Cellular Physiology Cell Physiol Biochem 2017;44:1411-1424 \\ \begin{tabular}{l|l|l}
\hline DOI: 10.1159/000485537 & $\begin{array}{l}\text { C) } 2017 \text { The Author(s). Published by S. Karger AG, Basel } \\
\text { www.karger.com/cpb }\end{array}$ \\
\hline Published online: November 30, 2017 Biochemistry
\end{tabular}}

Eichler et al.: Retinal Ganglion Cell Survival: PEDF and STAT3 Activation

causing neuroprotection of RGCs is in agreement with previous findings showing that RGCs are protected by PEDF from glutamate- or trophic factor withdrawal-mediated cytotoxicity [51]. Our findings, using an approach that involves culture of RGCs in the presence of MCM, are also consistent with known experimental data demonstrating an increased survival of neonatal RGCs in culture in the presence of MCM [49].

An important question is how PEDF transduces survival-promoting signals into neuronal cells. The identity and function(s) of receptor(s) for PEDF are not well defined, whereas the intracellular signaling pathways that generate pro-survival signals are better understood. Critical intracellular molecules accounting for PEDF-regulated survival signals in neuronal cells include NF- $\mathrm{BB} /$ Rel transcription factors and the cyclic AMP-responsive element binding protein (CREB) $[2,52,53]$. Perhaps the best understood PEDF-regulated pro-survival signaling pathway involves NF- $\kappa$ B activation, which regulates neuronal survival, as shown in both immature and mature cerebellar granule cells [53]. This pathway culminates in the transcriptional activation of genes encoding for neuroprotective proteins including several cytokines or proteins that counteract apoptosis. Indeed, PEDF was shown to act on neuronal cells to induce the expression of NGF, BDNF, GDNF, Bcl-2 and Bcl- $x_{\mathrm{L}}[2,53]$ and a downregulation of the activity of apoptosis inducing factor (AIF) [40]. A further recently disclosed function of PEDF-mediated NF- $\mathrm{BB}$ activation is related to specific prevention of transcriptional nuclear receptor co-repressor ( $\mathrm{N}-\mathrm{CoR}$ ) binding to Notch-responsive promoters, enhancing the transcriptional activity of Notch and thus regulating self-renewal of neural stem cells [54].

We show here, for the first time, that PEDF promotes RGC survival via activation of STAT3 (Fig. 3A and 5C). Of note, our experiments suggest that glial-derived mediators in MCM are capable of inducing STAT3 activation in RGCs. Increased STAT3 activation induced by these mediators, however, was substantially impaired in PEDF-R-deficient R28 cells suggesting that an important mediator is PEDF to account for this effect (Fig. 4C). However, the exact mechanism by which PEDF/ PEDF-R stimulation leads to STAT3 activation in neuronal cells remains to be elucidated. We did not determine further signaling molecule(s), which may be presumably intercalated between PEDF-R engagement and STAT3 activation; this was beyond the scope of this study and will be a subject of future work. A previous study with a prostate cancer cell line provided evidence that PEDF, acting in a concentration similar to ours, induces STAT3 expression, which was regulated by NF-kB transcriptional activity [55]. These findings open up the possibility that PEDF-induced activation of NF- $\mathrm{BB}$ / Rel (see above) may potentially be linked to STAT3 activation. Whether this is a mechanism that also applies to RGCs remains to be determined. Another conceivable proximal event that couples PEDF-R to STAT3 activation may involve a stimulation of the phospholipase A2 activity of PEDF-R to promote the release of arachidonic acid, which may then access a hitherto not defined signaling cascade that activates STAT3. However, in view of PEDFinduced STAT3 phosphorylation, which occurred rapidly upon stimulation (10-20 min; see Fig. 3B), we consider it unlikely that an indirect effect based on STAT3-stimulating cytokines, for example, IL-6, contributes to PEDF-mediated STAT3 activation.

The JAK/STAT3 signaling pathway has been recognized as important in stimulating the expression of a number of genes to control cellular survival and proliferation, thus playing a key role for neuronal survival [56]. In the retina, activation of JAK/STAT3 signaling is a mechanism that promotes RGC survival in response to stress. STAT3 activation is induced, for example, by intraocular pressure elevation or ischemia/reperfusion $[57,58]$. In addition, stress conditions may cause increasing gene expression of STAT3 in RGCs, as a mechanism to influence the balance between pro-survival and pro-apoptotic pathways in glaucomatous RGCs [59]. However, the precise mechanism whereby STAT3 signaling controls the survival of retinal neuronal cells remains to be elucidated. One mechanism is related to the abovementioned possibility that STAT3 signaling may operate by cross-talking with NF- $\kappa B$ signaling and/or other signaling cascades, which are stimulated by neuroprotective mediators. Further such signaling cascades being of potential importance for RGC survival are the ERK-1/ -2, p38 MAP kinase and PI3 kinase/Akt pathways [60-64], the activation of which by several

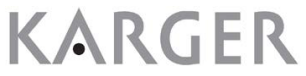


neuroprotectants can protect retinal cells, for example, against hyperglycemia- and oxidative stress-induced injury [61-63].

Our data indicate the possibility that Müller cell-derived PEDF induces STAT3 activation via engagement of PEDF-R. Indeed, PEDF-R-ablated cells demonstrated reduced STAT3 activation when exposed to MCM or PEDF (Fig. 4C, D) suggesting that PEDF-R is involved in PEDF-induced STAT3 phosphorylation. Therefore we hypothesize that STAT3 activation mediated via PEDF-R is a mechanism that regulates PEDF-promoted RGC survival. This idea is consistent with our experimental data showing that (i) PEDF-R ablation leads to a decreasing viability of PEDF-exposed R28 cells (Fig. 5A), and (ii) pharmacological inhibition of STAT3 signaling inhibited the survival of PEDF-exposed RGCs in response to trophic factor withdrawal or under hypoxia (Fig. 5C). However, our findings raise the question of why a limited survival seems to be inherent to PEDF-R-deficient cells as compared with control cells (Fig. 5A). There is evidence to suggest that PEDF-R expression interferes with cell viability under stress conditions. Previous findings with retinal pigment epithelial cells exposed to oxidative stress suggest that cells displaying comparably low PEDF-R levels are less protected from cell death [65]. Regarding the phospholipase A2 activity of PEDF-R $[25,26,65]$ it is conceivable that an alternative pathway exists for this molecule, which promotes neuronal survival independent of PEDF engagement, due either to an intrinsically constitutively activity or binding by (a) not yet defined mediator(s). However, this possibility remains to be investigated in future work.

We considered it possible that neuroprotective and tissue-regenerating effects are more obvious when PEDF acts in a cooperative manner. Since IL-6 is a prototypic JAK/STAT3 signaling inducer, we have investigated whether PEDF and IL-6 would exert combined (additive) neuroprotective effects on RGCs and whether signaling induced by both factors converges in the STAT3 pathway. IL- 6 is a cytokine that acts to support the survival of RGCs [66], and its activity can promote the neurite growth of mature RGCs in a JAK/STAT3dependent manner, thereby transforming RGCs into an active regenerative state [32]. However, we found that PEDF and IL-6 did not exert an additive effect on RGC survival (Fig. 1) and that the concerted action of both factors did not induce a stronger activation of STAT3, when compared with cells in the presence of either factor alone (Fig. 3D). These findings suggest that each PEDF- or IL-6-mediated STAT3 signaling is sufficient to promote RGC survival and that both PEDF-mediated STAT3 and NF- $\kappa$ B pathways control similar transcriptional rates of pro-survival genes.

\section{Conclusion}

In summary, we show that PEDF protects RGCs against cell death based on a STAT3dependent signaling pathway. Our findings strongly suggest that Müller cell-derived PEDF is an active neuroprotectant available in the cocktail of soluble factors produced by Müller glial cells. In this regard, Müller cells are a promising cellular target to increase neuroprotection in the retina, for example, for improving optic nerve regeneration. A conceivable avenue may thus comprise supporting or enhancing the secretory function of Müller cells, possibly along with preventing glial cell deficiency.

\section{Acknowledgements}

This work was supported by grants from Deutsche Forschungsgemeinschaft (grant numbers RE 849/14-2 and UN 37512.1). We also gratefully acknowledge financial support by an intramural program of the Medical Faculty, University of Leipzig. The authors wish to thank Ute Weinbrecht for valuable technical support.

\section{Disclosure Statement}

Authors declare no commercial Disclosure Statement. 


\section{Cellular Physiology Cell Physiol Biochem 2017;44:1411-1424 \begin{tabular}{l|l} 
and Biochemistry & DOI: 10.1159/000485537 \\
Published 2017 The Author(s). Published by S. Karger AG, Basel \\
www.karger.com/cpb
\end{tabular}}

Eichler et al.: Retinal Ganglion Cell Survival: PEDF and STAT3 Activation

\section{References}

1 Becerra SP, Notario V: The effects of PEDF on cancer biology: mechanisms of action and therapeutic potential. Nat Rev Cancer 2013;13:258-271.

-2 Barnstable CJ, Tombran-Tink J: Neuroprotective and antiangiogenic actions of PEDF in the eye: molecular targets and therapeutic potential. Prog Retin Eye Res 2004;23:561-577.

- Friedman DS, Wolfs RC, O’Colmain BJ, Klein BE, Taylor HR, West S, Leske MC, Mitchell P, Congdon N, Kempen J: Prevalence of open-angle glaucoma among adults in the United States. Arch Ophthalmol 2004;122:532-538.

4 Quigley HA, Broman AT: The number of people with glaucoma worldwide in 2010 and 2020. Br J Ophthalmol 2006;90:262-267.

5 Liew G, Michaelides M, Bunce C: A comparison of the causes of blindness certifications in England and Wales in working age adults (16-64 years), 1999-2000 with 2009-2010. BMJ Open 2014;4:e004015.

6 Osborne NN, Casson RJ, Wood JP, Chidlow G, Graham M, Melena J: Retinal ischemia: mechanisms of damage and potential therapeutic strategies. Prog Retin Eye Res 2004;23:91-147.

7 Amin RH, Frank RN, Kennedy A, Eliott D, Puklin JE, Abrams GW: Vascular endothelial growth factor is present in glial cells of the retina and optic nerve of human subjects with nonproliferative diabetic retinopathy. Invest Ophthalmol Vis Sci 1997;38:36-47.

-8 Eichler W, Yafai Y, Wiedemann P, Reichenbach A: Angiogenesis-related factors derived from retinal glial (Müller) cells in hypoxia. Neuroreport 2004;15:1633-1637.

-9 Harada T, Harada C, Nakayama N, Okuyama S, Yoshida K, Kohsaka S, Matsuda H, Wada K: Modification of glial-neuronal cell interactions prevents photoreceptor apoptosis during light-induced retinal degeneration. Neuron 2000;26:533-541.

10 Harada T, Harada C, Kohsaka S, Wada E, Yoshida K, Ohno S, Mamada H, Tanaka K, Parada LF, Wada K: Microglia-Müller glia cell interactions control neurotrophic factor production during light-induced retinal degeneration. J Neurosci 2002;22:9228-9236.

-11 Neophytou C, Vernallis AB, Smith A, Raff MC: Müller-cell-derived leukaemia inhibitory factor arrests rod photoreceptor differentiation at a postmitotic pre-rod stage of development. Development 1997;124:23452354.

12 Seki M, Tanaka T, Sakai Y, Fukuchi T, Abe H, Nawa H, Takei N: Müller Cells as a source of brain-derived neurotrophic factor in the retina: noradrenaline upregulates brain-derived neurotrophic factor levels in cultured rat Müller cells. Neurochem Res 2005;30:1163-1170.

-13 Stone J, Itin A, Alon T, Pe'er J, Gnessin H, Chan-Ling T, Keshet E: Development of retinal vasculature is mediated by hypoxia-induced vascular endothelial growth factor (VEGF) expression by neuroglia. J Neurosci 1995;15:4738-4747.

14 Unterlauft JD, Eichler W, Kuhne K, Yang XM, Yafai Y, Wiedemann P, Reichenbach A, Claudepierre T: Pigment epithelium-derived factor released by Müller glial cells exerts neuroprotective effects on retinal ganglion cells. Neurochem Res 2012;37:1524-1533.

15 Walsh N, Valter K, Stone J: Cellular and subcellular patterns of expression of bFGF and CNTF in the normal and light stressed adult rat retina. Exp Eye Res 2001;72:495-501.

16 Wen R, Tao W, Li Y, Sieving PA: CNTF and retina. Prog Retin Eye Res 2012;31:136-151.

17 Ogata N, Wang L, Jo N, Tombran-Tink J, Takahashi K, Mrazek D, Matsumura M: Pigment epithelium derived factor as a neuroprotective agent against ischemic retinal injury. Curr Eye Res 2001;22:245-252.

-18 Takita H, Yoneya S, Gehlbach PL, Duh EJ, Wei LL, Mori K: Retinal neuroprotection against ischemic injury mediated by intraocular gene transfer of pigment epithelium-derived factor. Invest Ophthalmol Vis Sci 2003;44:4497-4504.

19 Bilak MM, Corse AM, Bilak SR, Lehar M, Tombran-Tink J, Kuncl RW: Pigment epithelium-derived factor (PEDF) protects motor neurons from chronic glutamate-mediated neurodegeneration. J Neuropathol Exp Neurol 1999;58:719-728.

20 Cao W, Tombran-Tink J, Elias R, Sezate S, Mrazek D, McGinnis JF: In vivo protection of photoreceptors from light damage by pigment epithelium-derived factor. Invest Ophthalmol Vis Sci 2001;42:1646-1652.

-21 Cao W, Tombran-Tink J, Chen W, Mrazek D, Elias R, McGinnis JF: Pigment epithelium-derived factor protects cultured retinal neurons against hydrogen peroxide-induced cell death. J Neurosci Res 1999;57:789-800.

22 Cayouette M, Smith SB, Becerra SP, Gravel C: Pigment epithelium-derived factor delays the death of photoreceptors in mouse models of inherited retinal degenerations. Neurobiol Dis 1999;6:523-532. 


\section{Cellular Physiology Cell Physiol Biochem 2017;44:1411-1424 \begin{tabular}{ll|l} 
DOI: 10.1159/000485537 & $\begin{array}{l}\text { O } 2017 \text { The Author(s). Published by S. Karger AG, Basel } \\
\text { www.karger.com/cpb }\end{array}$ \\
\hline and Biochemistry
\end{tabular}}

23 Miyazaki M, Ikeda Y, Yonemitsu Y, Goto Y, Sakamoto T, Tabata T, Ueda Y, Hasegawa M, Tobimatsu S, Ishibashi T, Sueishi K: Simian lentiviral vector-mediated retinal gene transfer of pigment epithelium-derived factor protects retinal degeneration and electrical defect in Royal College of Surgeons rats. Gene Ther 2003;10:1503-1511.

-24 Unterlauft JD, Claudepierre T, Schmidt M, Müller K, Yafai Y, Wiedemann P, Reichenbach A, Eichler W: Enhanced survival of retinal ganglion cells is mediated by Müller glial cell-derived PEDF. Exp Eye Res 2014;127C:206-214.

25 Notari L, Baladron V, Aroca-Aguilar JD, Balko N, Heredia R, Meyer C, Notario PM, Saravanamuthu S, Nueda ML, Sanchez-Sanchez F, Escribano J, Laborda J, Becerra SP: Identification of a lipase-linked cell membrane receptor for pigment epithelium-derived factor. J Biol Chem 2006;281:38022-38037.

26 Subramanian P, Locatelli-Hoops S, Kenealey J, DesJardin J, Notari L, Becerra SP: Pigment epitheliumderived factor (PEDF) prevents retinal cell death via PEDF Receptor (PEDF-R): identification of a functional ligand binding site. J Biol Chem 2013;288:23928-23942.

27 Tombran-Tink J: The neuroprotective and angiogenesis inhibitory serpin, PEDF: new insights into phylogeny, function, and signaling. Front Biosci 2005;10:2131-2149.

-28 Mey J, Thanos S: Intravitreal injections of neurotrophic factors support the survival of axotomized retinal ganglion cells in adult rats in vivo. Brain Res 1993;602:304-317.

29 Takahata K, Katsuki H, Kume T, Ito K, Tochikawa Y, Muraoka S, Yoneda F, Kashii S, Honda Y, Akaike A: Retinal neurotoxicity of nitric oxide donors with different half-life of nitric oxide release: involvement of N-methylD-aspartate receptor. J Pharmacol Sci 2003;92:428-432.

-30 Ji JZ, Elyaman W, Yip HK, Lee VW, Yick LW, Hugon J, So KF: CNTF promotes survival of retinal ganglion cells after induction of ocular hypertension in rats: the possible involvement of STAT3 pathway. Eur J Neurosci 2004;19:265-272.

-31 Elsaeidi F, Bemben MA, Zhao XF, Goldman D: Jak/Stat signaling stimulates zebrafish optic nerve regeneration and overcomes the inhibitory actions of Socs3 and Sfpq. J Neurosci 2014;34:2632-2644.

-32 Leibinger M, Andreadaki A, Diekmann H, Fischer D: Neuronal STAT3 activation is essential for CNTF- and inflammatory stimulation-induced CNS axon regeneration. Cell Death Dis 2013;4:e805.

33 Müller A, Hauk TG, Fischer D: Astrocyte-derived CNTF switches mature RGCs to a regenerative state following inflammatory stimulation. Brain 2007;130:3308-3320.

34 Müller A, Hauk TG, Leibinger M, Marienfeld R, Fischer D: Exogenous CNTF stimulates axon regeneration of retinal ganglion cells partially via endogenous CNTF. Mol Cell Neurosci 2009;41:233-246.

-35 Reichenbach A, Fromter C, Engelmann R, Wolburg H, Kasper M, Schnitzer J: Müller glial cells of the tree shrew retina. J Comp Neurol 1995;360:257-270.

-36 Seigel GM, Mutchler AL, Imperato EL: Expression of glial markers in a retinal precursor cell line. Mol Vis 1996;2:2.

37 Seigel GM: The golden age of retinal cell culture. Mol Vis 1999;5:4.

-38 Notari L, Miller A, Martinez A, Amaral J, Ju M, Robinson G, Smith LE, Becerra SP: Pigment epitheliumderived factor is a substrate for matrix metalloproteinase type 2 and type 9: implications for downregulation in hypoxia. Invest Ophthalmol Vis Sci 2005;46:2736-2747.

-39 Eichler W, Yafai Y, Keller T, Wiedemann P, Reichenbach A: PEDF derived from glial Müller cells: a possible regulator of retinal angiogenesis. Exp Cell Res 2004;299:68-78.

40 Murakami Y, Ikeda Y, Yonemitsu Y, Onimaru M, Nakagawa K, Kohno R, Miyazaki M, Hisatomi T, Nakamura M, Yabe T, Hasegawa M, Ishibashi T, Sueishi K: Inhibition of nuclear translocation of apoptosis-inducing factor is an essential mechanism of the neuroprotective activity of pigment epithelium-derived factor in a rat model of retinal degeneration. Am J Pathol 2008;173:1326-1338.

-41 Yafai Y, Lange J, Wiedemann P, Reichenbach A, Eichler W: Pigment epithelium-derived factor acts as an opponent of growth-stimulatory factors in retinal glial-endothelial cell interactions. Glia 2007;55:642-651.

-42 Hu Y, Chen Y, Lin M, Lee K, Mott RA, Ma JX: Pathogenic role of the Wnt signaling pathway activation in laserinduced choroidal neovascularization. Invest Ophthalmol Vis Sci 2013;54:141-154.

43 Bernard A, Gao-Li J, Franco CA, Bouceba T, Huet A, Li Z: Laminin receptor involvement in the antiangiogenic activity of pigment epithelium-derived factor. J Biol Chem 2009;284:10480-10490

44 Sohn J, Selvaraj V, Wakayama K, Orosco L, Lee E, Crawford SE, Guo F, Lang J, Horiuchi M, Zarbalis K, Itoh T, Deng W, Pleasure D: PEDF is a novel oligodendrogenic morphogen acting on the adult SVZ and corpus callosum. J Neurosci 2012;32:12152-12164. 


\section{Cellular Physiology Cell Physiol Biochem 2017;44:1411-1424

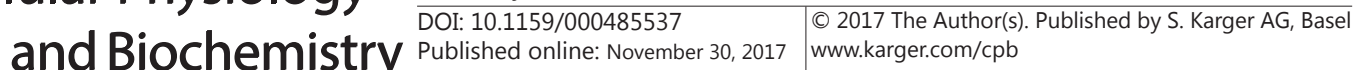

45 Schust J, Sperl B, Hollis A, Mayer TU, Berg T: Stattic: a small-molecule inhibitor of STAT3 activation and dimerization. Chem Biol 2006;13:1235-1242.

-46 Bringmann A, Pannicke T, Grosche J, Francke M, Wiedemann P, Skatchkov SN, Osborne NN, Reichenbach A: Müller cells in the healthy and diseased retina. Prog Retin Eye Res 2006;25:397-424.

47 Hernandez MR: The optic nerve head in glaucoma: role of astrocytes in tissue remodeling. Prog Retin Eye Res 2000;19:297-321.

48 Armson PF, Bennett MR, Raju TR: Retinal ganglion cell survival and neurite regeneration requirements: the change from Müller cell dependence to superior colliculi dependence during development. Brain Res 1987;429:207-216.

49 Raju TR, Bennett MR: Retinal ganglion cell survival requirements: a major but transient dependence on Müller glia during development. Brain Res 1986;383:165-176.

50 Hauk TG, Müller A, Lee J, Schwendener R, Fischer D: Neuroprotective and axon growth promoting effects of intraocular inflammation do not depend on oncomodulin or the presence of large numbers of activated macrophages. Exp Neurol 2008;209:469-482.

-51 Pang IH, Zeng H, Fleenor DL, Clark AF: Pigment epithelium-derived factor protects retinal ganglion cells. BMC Neurosci 2007;8:11.

52 Yabe T, Wilson D, Schwartz JP: NFkappaB activation is required for the neuroprotective effects of pigment epithelium-derived factor (PEDF) on cerebellar granule neurons. J Biol Chem 2001;276:43313-43319.

53 Yabe T, Kanemitsu K, Sanagi T, Schwartz JP, Yamada H: Pigment epithelium-derived factor induces prosurvival genes through cyclic AMP-responsive element binding protein and nuclear factor kappa B activation in rat cultured cerebellar granule cells: Implication for its neuroprotective effect. Neuroscience 2005;133:691-700.

54 Andreu-Agulló C, Morante-Redolat JM, Delgado AC, Fariñas I: Vascular niche factor PEDF modulates Notchdependent stemness in the adult subependymal zone. Nat Neurosci 2009;12:1514-1523.

-55 Smith ND, Schulze-Hoepfner FT, Veliceasa D, Filleur S, Shareef S, Huang L, Huang XM, Volpert OV: Pigment epithelium-derived factor and interleukin-6 control prostate neuroendocrine differentiation via feedforward mechanism. J Urol 2008;179:2427-2434.

56 Battle TE, Frank DA: The role of STATs in apoptosis. Curr Mol Med 2002;2:381-392.

57 Huang Y, Cen LP, Choy KW, van Rooijen N, Wang N, Pang CP, Cui Q: JAK/STAT pathway mediates retinal ganglion cell survival after acute ocular hypertension but not under normal conditions. Exp Eye Res 2007;85:684-695.

58 Zhang C, Li H, Liu MG, Kawasaki A, Fu XY, Barnstable CJ, Shao-Min Zhang S: STAT3 activation protects retinal ganglion cell layer neurons in response to stress. Exp Eye Res 2008;86:991-997.

59 Wang DY, Ray A, Rodgers K, Ergorul C, Hyman BT, Huang W, Grosskreutz CL: Global gene expression changes in rat retinal ganglion cells in experimental glaucoma. Invest Ophthalmol Vis Sci 2010;51:40844095.

-60 Park K, Luo JM, Hisheh S, Harvey AR, Cui Q: Cellular mechanisms associated with spontaneous and ciliary neurotrophic factor-cAMP-induced survival and axonal regeneration of adult retinal ganglion cells. J Neurosci 2004;24:10806-10815.

61 Veluthakal R, Kumar B, Mohammad G, Kowluru A, Kowluru RA: Tiam1-Rac1 Axis Promotes Activation of p38 MAP Kinase in the Development of Diabetic Retinopathy: Evidence for a Requisite Role for Protein Palmitoylation. Cell Physiol Biochem 2015;36:208-220.

62 Zhou RM, Shen Y, Yao J, Yang H, Shan K, Li XM, Jiang Q, Yan B: Nmnat 1: a Security Guard of Retinal Ganglion Cells (RGCs) in Response to High Glucose Stress. Cell Physiol Biochem 2016;38:2207-2218.

-63 Zha X, Wu G, Zhao X, Zhou L, Zhang H, Li J, Ma L, Zhang Y: PRDX6 Protects ARPE-19 Cells from Oxidative Damage via PI3K/AKT Signaling. Cell Physiol Biochem 2015;36:2217-2228.

64 Klöcker N, Kermer P, Weishaupt JH, Labes M, Ankerhold R, Bähr M: Brain-derived neurotrophic factormediated neuroprotection of adult rat retinal ganglion cells in vivo does not exclusively depend on phosphatidyl-inositol-3'-kinase/protein kinase B signaling. J Neurosci 2000;20:6962-6967.

65 Subramanian P, Mendez EF, Becerra SP: A Novel Inhibitor of 5-Lipoxygenase (5-LOX) Prevents Oxidative Stress-Induced Cell Death of Retinal Pigment Epithelium (RPE) Cells. Invest Ophthalmol Vis Sci 2016;57:4581-4588.

66 Sánchez RN, Chan CK, Garg S, Kwong JM, Wong MJ, Sadun AA, Lam TT: Interleukin-6 in retinal ischemia reperfusion injury in rats. Invest Ophthalmol Vis Sci 2003;44:4006-4011. 